\title{
Alternativa para redução do consumo de água potável no processo da indústria de transformação de plásticos
}

O aproveitamento das águas da chuva vem sendo utilizado para diminuir os impactos ambientais causados pelos mais diversos setores industriais, pois estas águas podem ser utilizadas em uma parte do processo ou em substituição total da água necessária, variando de acordo com as demandas e o porte da fábrica ou sistema utilizado. Diante disso, este trabalho buscou avaliar a viabilidade econômica e técnica do uso das águas pluviais no processo de produção de pré-formas (PET) reduzindo em torno de $20 \%$ do consumo de água potável, em uma indústria de transformação situada no município de Cabo de Santo Agostinho, estado de Pernambuco. Para tanto foram testados métodos de dimensionamentos distintos, bem como analises físico-químicas da água coletada na região. A escolha do método mais adequado deu-se pelos critérios de maior índice de confiança, percentual de atendimento da demanda em torno de $20 \%$ e menor payback. Os resultados obtidos indicaram que a demanda hídrica da indústria avaliada apresenta uma média diária de consumo igual a 47,04 m3, e a possibilidade de implantação do sistema com capacidade de $250 \mathrm{m3}$, com potencial de captação de água pluvial da ordem de $20 \%$ da demanda total, com uma economia estimada em $\$ 14.695,5$ por ano e com payback de 30 meses.

\section{Alternative to reduce drinking water consumption in the plastics processing industry}

\begin{abstract}
The use of rainwater has been used to reduce the environmental impacts caused by the most diverse industrial sectors, as these waters can be used in a part of the process or in total replacement of the necessary water, varying according to the demands and the size of the water. factory or system used. Therefore, this work sought to evaluate the economic and technical feasibility of using rainwater in the preform production process (PET), reducing around $20 \%$ of drinking wate consumption, in a processing industry located in the municipality of Cabo of Santo Agostinho, state of Pernambuco. For that, different dimensioning methods were tested, as well as physical-chemical analyzes of the water collected in the region. The choice of the most appropriate method was made based on the criteria of greater confidence index, percentage of meeting demand around $20 \%$ and lower payback. The results obtained indicated that the water demand of the evaluated industry presents a daily average of consumption equal to $47.04 \mathrm{m3}$, and the possibility of implanting the system with a capacity of $250 \mathrm{~m} 3$, with a potential to capture rainwater in the order of $20 \%$ of the total demand, with savings estimated at $\$ 14,695.5$ per year and with a $30-$ month payback.
\end{abstract}

Keywords: Capture; Payback; Reception; Roof; Economic viability.

Topic: Engenharia de Recursos Hídricos

Reviewed anonymously in the process of blind peer.
Received: $10 / 12 / 2019$

Approved: 14/01/2020
Daniele de Castro Pessoa de Melo (iD

Instituto de Tecnologia de Pernambuco, Brasil

http://lattes.cnpq.br/4010783198064867

http://orcid.org/0000-0003-4058-092X

daniele.castro@itep.br

Domingos Joaquim de Freitas (iD

Instituto de Tecnologia de Pernambuco, Brasil

http://lattes.cnpq.br/1410166117204004

http://orcid.org/0000-0003-2034-1534

domingoscalado@hotmail.com
Referencing this:

FREITAS, D. J.; MELO, D. C. P.. Alternativa para redução do consumo de água potável no processo da indústria de transformação de plásticos. Revista Ibero Americana de Ciências Ambientais, v.11, n.1, p.115130, 2020. DOI: http://doi.org/10.6008/CBPC21796858.2020.001.0012 


\section{INTRODUÇÃO}

O desenvolvimento tecnológico e o aumento da densidade demográfica trouxeram como consequências diversos problemas ao meio ambiente, dentre a gama de desajustes gerados, Donato et al. (2015) destacam-se: o crescimento desordenado da população mundial, desmatamento das florestas, aceleração dos processos de mudanças climáticas e o aquecimento global. Tais problemáticas, na visão de Amorim et al. (2016) permitiram o desenvolvimento de uma significativa preocupação quanto a utilização de recursos naturais renováveis e não renováveis, bem como subsidiou a necessidade pela busca por alternativas que minimizem os impactos causados pelo uso desordenado desses recursos.

As indústrias de transformação, por exemplo, são extremamente úteis para suprir as demandas econômicas nas sociedades atuais, entretanto impetram de uma enorme quantidade de matéria prima para transformar um recurso em produto, associado ainda a necessidade de recursos energéticos e água. Segundo Padilla (2017), as indústrias de transformação de plástico vêm crescendo rapidamente, visto que na sociedade contemporânea se acentua cada vez mais o uso dos plásticos e associado a este crescimento está o acréscimo da demanda de matéria prima (petróleo) e materiais de processo (água e energia).

Por conta disso, nas últimas décadas, entidades governamentais e não governamentais estão à procura de soluções que minimizem a quantidade de materiais nos processos industriais, sem perder a qualidade do produto final. Na tentativa de equacionar aspectos de cunho ambiental, a ciência tem contribuído para o avanço de tecnologias mais limpas e do desenvolvimento de processos chamados 'super clean', caracterizadas pelo reúso ou diminuição da utilização de água nos processos produtivos.

Duarte et al. (2015) afirma que o aproveitamento das águas da chuva vem sendo utilizado para diminuir os impactos ambientais causados pelos mais diversos setores industriais, sejam pelas vantagens econômicas e ambientais apresentadas, pela simplicidade da sua implementação, ou pela dinâmica de utilização, pois Silva et al. (2017) descreve que essas águas podem ser utilizados em uma parte do processo ou em substituição total da água necessária, variando de acordo com as demandas e o porte da fábrica ou sistema utilizado.

Nos últimos anos, as preocupações relacionadas ao meio ambiente têm ganhado força e a água vem se destacando cada vez mais, principalmente no que concerne aos aspectos de preservação, contaminação e desperdícios do recurso. Diante da crescente escassez do bem, faz-se necessária a adoção de estratégias que garanta um consumo mais controlado, eficiente e sustentável desse recurso tão essencial para as diversas formas de vida existentes no planeta.

O consumo de água potável é relativamente alto na indústria em geral, e para Souza et al. (2018) as indústrias de fabricação de pré-forma PET estão inclusas neste contexto. Diante dessa realidade, este estudo propõe uma alternativa para reduzir o consumo de água potável no processo produtivo. Realizada pela substituição de parte da água potável proveniente da distribuição pública, por águas pluviais captadas a partir do telhado do prédio da empresa. O uso de águas pluviais nos processos produtivos pode reduzir o consumo de água potável e com isso, gerar uma economia ao mesmo tempo em que promove o uso sustentável dos 
recursos naturais.

Diante disso, o objetivo do presente trabalho foi avaliar a viabilidade econômica e técnica do uso das águas pluviais no processo de produção de pré-formas (PET), na redução do consumo de água potável fornecida pela concessionária, em uma indústria de transformação situada no município de Cabo de Santo Agostinho, estado de Pernambuco, Brasil.

\section{METODOLOGIA}

\section{Caracterização da área de estudo}

O empreendimento avaliado durante a realização do presente estudo é uma indústria de pré-formas (PET), localizada no distrito industrial do município de Cabo de Santo Agostinho/PE (Figura 1), determinado pelas coordenadas 0817'12" S e 3502'06" W. A indústria avaliada funciona na região desde o ano de 2009 e apresenta uma área construída de aproximadamente $4.000 \mathrm{~m}^{2}$, cuja capacidade de transformação mensal média é da ordem de 2.000 toneladas de resina PET por mês, operando em um regime de 24 horas por dia, 07 dias por semana e 365 dias por ano, e contando com um quadro de 104 funcionários.

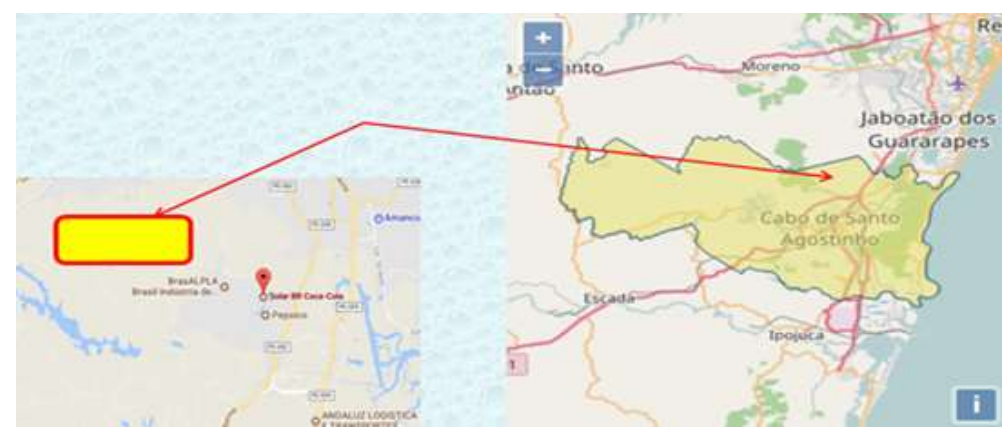

Figura 1: Localização da área de estudo. Fonte: Adaptado Google Earth (2019).

\section{Demanda hídrica do empreendimento}

Nesta etapa de desenvolvimento do estudo, foi realizado o levantamento das características de qualidade e quantidade de água demandada pela indústria de pré-formas e suas respectivas fontes. Esta etapa foi composta pelas seguintes atividades: a) Descrição das atividades realizadas na indústria; b) Caracterização da demanda hídrica necessária em cada processo descrito anteriormente; c) Avaliar quantitativa e qualitativamente as águas pluviais para uso no processo produtivo no local em estudo.

\section{Precipitação na Região}

Foi realizado o levantamento do histórico pluviométrico na região afim de determinar um perfil da disponibilidade hídrica ao longo dos anos. Foram utilizadas médias mensais e anuais sazonais de precipitação das séries históricas de dados pluviométricos da Região do Cabo de Santo Agostinho, obtidos da APAC (Agência Pernambucana de água de Climas). Estes dados foram submetidos a uma análise para avaliação das séries históricas e posteriormente consistidos. Foram utilizados dados pluviométricos de 2004 a 2017. 


\section{Qualidade da água}

A qualidade da água pluvial é um parâmetro que varia no espaço e no tempo. Esta variabilidade devese não só às condições da superfície de captação e armazenamento, mas também às condições atmosféricas da região e independente desses fatores, ainda existe a necessidade de monitoramento da qualidade da água, visto que como é inerente ao processo industrial, terá existência do tratamento químico. Nesta perspectiva, foram realizadas análises de qualidade de água, afim de avaliar as principais características da água coletada na região da indústria em estudo, este levantamento foi realizado apenas para verificar o perfil de potabilidade da água coletada na região. Existem diversos tipos de análises químicas, entretanto optouse pela realização das análises do Quadro 1 (FUNASA, 2013).

Tabela 1: Descrição das análises químicas da água.

\begin{tabular}{|c|c|}
\hline Análises & Descrição \\
\hline Alcalinidade Total & $\begin{array}{l}\text { Dada pelo somatório das diferentes formas de alcalinidade existentes, expressa em termos de carbonato de } \\
\text { cálcio. A alcalinidade mede a capacidade da água em neutralizar os ácidos }\end{array}$ \\
\hline Dureza Total & $\begin{array}{l}\text { A dureza total é calculada como sendo a soma das concentrações de íons cálcio e magnésio na água, } \\
\text { expressos como carbonato de cálcio. }\end{array}$ \\
\hline Cloretos & $\begin{array}{l}\text { Os cloretos estão presentes em águas brutas e tratadas em concentrações que podem variar de pequenos } \\
\text { traços até centenas de } \mathrm{mg} / \mathrm{L} \text {. Estão presentes na forma de cloretos de sódio, cálcio e magnésio. }\end{array}$ \\
\hline $\mathrm{pH}$ & $\begin{array}{l}\text { Representa a concentração de íons hidrogênio em uma solução. Esse fator é de excepcional importância, } \\
\text { principalmente nos processos de tratamento, pois seus valores são necessários para melhorar o processo } \\
\text { de coagulação/floculação da água e também o controle da desinfeç̧ão. }\end{array}$ \\
\hline Turbidez & $\begin{array}{c}\text { A turbidez da água é devido à presença de materiais sólidos em suspensão, que reduzem a sua } \\
\text { transparência. Pode ser provocada também pela presença de algas, plâncton, matéria orgânica e muitas } \\
\text { outras substâncias como o zinco, ferro, manganês e areia, resultantes do processo natural de erosão ou de } \\
\text { despejos domésticos e industriais }\end{array}$ \\
\hline
\end{tabular}

\section{Dimensionamento do Sistema de Aproveitamento das Águas Pluviais - SAAP}

Os testes de dimensionamento do sistema foram baseados na planta baixa da indústria em estudo (Figura 2). E cenários de dimensionamento foram desenvolvidos para cada método, considerando a necessidade de uma economia aproximada de $20 \%$ da água potável utilizada pela indústria avaliada.

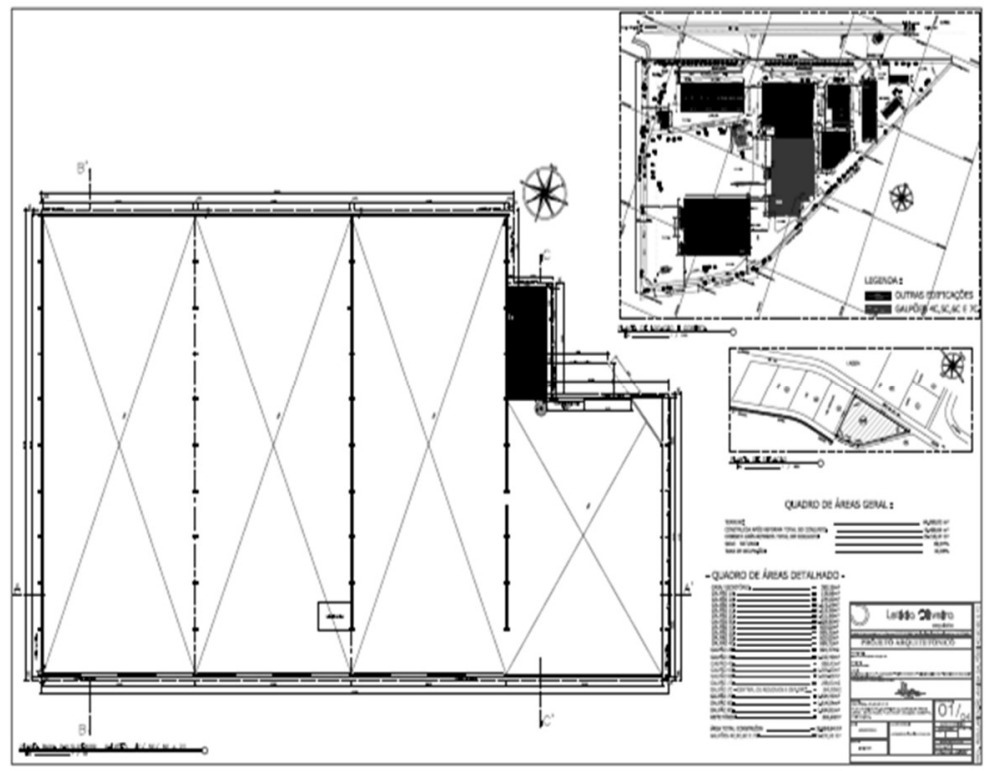

Figura 2: Planta baixa da indústria em estudo.

O dimensionamento do SAAP será realizado de acordo com a NBR 15.527 (ABNT, 2007), referente ao 
aproveitamento da chuva por coberturas em áreas urbanas para fins não potáveis. Neste trabalho foram testados os métodos de Rippl, Simulação, Azevedo Neto, Prático Alemão, Prático Inglês, Prático Australiano e a Simulação realizada pelo software Netuno (Tabela 2).

Tabela 2: Descrição de fórmulas utilizadas para o dimensionamento da SAAP.

\begin{tabular}{|c|c|c|}
\hline MÉTODO & FÓRMULA & DESCRIÇÃO DAS VARIÁVEIS \\
\hline \multirow[t]{6}{*}{ RIPPL } & \multirow{6}{*}{$S_{(t)}=D_{(t)}-Q_{(t)}$} & $\mathrm{S}(\mathrm{t})=$ volume de água no reservatório no tempo $\mathrm{t}$, expresso em metros cúbicos $\left(\mathrm{m}^{3}\right)$; \\
\hline & & $\mathrm{Q}(\mathrm{t})=$ volume de chuva aproveitável no tempo $\mathrm{t}$, expresso em metros cúbicos $\left(\mathrm{m}^{3}\right) ;$ \\
\hline & & $\mathrm{D}(\mathrm{t})=$ demanda ou consumo no tempo $\mathrm{t}$, expressa em metros cúbicos \\
\hline & & $\left(m_{3}\right)$ \\
\hline & & $V=$ volume do reservatório, expresso em metros cúbicos $\left(\mathrm{m}^{3}\right) ;$ \\
\hline & & $\mathrm{C}=$ coeficiente de escoamento superficial. \\
\hline \multirow[t]{6}{*}{ SIMULAÇÃO } & \multirow{6}{*}{$S_{(t)}+S_{(t-1)}-D_{(t)}$} & $\mathrm{S}_{(\mathrm{t})}=$ volume de água no reservatório no tempo $\mathrm{t}$, expresso em metros cúbicos $\left(\mathrm{m}^{3}\right)$ \\
\hline & & $\begin{array}{l}\mathrm{S}_{(\mathrm{t}-1)}=\text { volume de água no reservatório no tempo } \mathrm{t}-1 \text {, expresso em metros cúbicos } \\
\left(\mathrm{m}^{3}\right) ;\end{array}$ \\
\hline & & $Q_{(t)}=$ volume de chuva no tempo $t$, expresso em metros cúbicos $\left(m^{3}\right) ;$ \\
\hline & & $D_{(t)}=$ consumo ou demanda no tempo $t$, expressa em metros cúbicos $\left(m^{3}\right) ;$ \\
\hline & & $\mathrm{V}=$ volume do reservatório fixado, expresso em metros cúbicos (m3); \\
\hline & & $\mathrm{C}=$ coeficiente de escoamento superficial. \\
\hline \multirow{4}{*}{$\begin{array}{l}\text { AZEVEDO } \\
\text { NETTO }\end{array}$} & \multirow[t]{4}{*}{$V=0,042 \cdot P \cdot A \cdot T$} & V = volume de água no reservatório ou volume do reservatório de água pluvial (L); \\
\hline & & $\mathrm{P}=$ precipitação média anual $(\mathrm{mm})$ \\
\hline & & $A=$ área de captação em projeção no terreno $\left(\mathrm{m}^{2}\right)$; \\
\hline & & $\mathrm{T}=$ número de meses de pouca chuva ou seca. \\
\hline \multirow{3}{*}{$\begin{array}{l}\text { PRÁTICO } \\
\text { ALEMÃO }\end{array}$} & \multirow[t]{3}{*}{$V_{\mathrm{i}}=\operatorname{mim}(V ; D) \cdot 0,06$} & $V_{i}=$ valor numérico do volume aproveitável de água da chuva anual (L); \\
\hline & & $D=$ valor numérico da demanda anual de água não potável (L); \\
\hline & & $V_{\text {adotado }}=$ valor numérico do volume de água no reservatório (L). \\
\hline \multirow{3}{*}{$\begin{array}{l}\text { PRÁTCO } \\
\text { INGLÊS }\end{array}$} & \multirow{3}{*}{$S=0,05 \cdot P \cdot A$} & $P=$ precipitação média anual $(\mathrm{mm})$ \\
\hline & & $A=$ área de captação $\left(\mathrm{m}^{2}\right)$ \\
\hline & & $S=$ volume do reservatório (litro). \\
\hline \multirow{4}{*}{$\begin{array}{l}\text { PRÁTICO } \\
\text { AUSTRALIAN } \\
\text { O }\end{array}$} & \multirow{4}{*}{$V_{t}=V_{t-1}+Q_{t}-D$} & Qt = volume mensal produzido pela chuva no mês $t$, expresso em metros cúbicos $\left(m^{3}\right)$; \\
\hline & & $\begin{array}{l}\text { Vt = volume de água que está no tanque no fim do mês t, expresso em metros cúbicos } \\
\left(\mathrm{m}^{3}\right)\end{array}$ \\
\hline & & $\begin{array}{l}\text { Vt-1 = volume de água que está no tanque no início do mês t, expresso em metros } \\
\text { cúbicos }\left(\mathrm{m}^{3}\right) ;\end{array}$ \\
\hline & & $\mathrm{Dt}=$ demanda mensal, expressa em metros cúbicos $\left(\mathrm{m}^{3}\right)$. \\
\hline NETUNO & & Seguindo a interfase do programa \\
\hline
\end{tabular}

\section{Verificação da viabilidade}

Nesta etapa serão comparados os gastos realizados sem e com a implantação do sistema de reaproveitamento das águas pluviais. A partir destes dados, associados a análise do retorno do investimento, é possível determinar a viabilidade do projeto proposto e o payback. Para calcular o retorno do investimento (payback simples), precisa-se conhecer o investimento inicial do projeto e dividindo-o pelo ganho que o projeto trará em um determinado período:

$$
X=\frac{(a+b+c)}{(d \cdot e)}
$$

Em que:

$a=$ Custo da estrutura de captação instalada; $b=$ Custo de construção da cisterna; $c=$ Custo de automação do sistema de bombeamento cisterna $\mathrm{x}$ processo produtivo; $d$ = Valor do metro cúbico de água potável; e $=$ Volume em metros cúbicos captados por mês; $X=$ Retorno do investimento. 


\section{RESULTADOS E DISCUSSÃO}

\section{Demanda hídrica do empreendimento}

Mesmo diante da crescente participação da indústria na demanda total de água e do impacto causado por alguns empreendimentos, pelo lançamento de efluentes nas bacias hidrográficas, o papel da água no setor industrial ainda é um assunto pouco estudado no Brasil. E a caracterização do uso industrial da água é de fundamental importância para se avaliar o impacto de políticas de gestão de recursos hídricos sobre o setor. Nesse contexto, a falta de conhecimento sobre o papel da água na indústria torna-se ainda mais grave, uma vez que pode acarretar sérios erros de avaliação quanto aos impactos financeiros e ambientais da cobrança sobre os usuários industriais.

Há uma grande variação nos padrões de uso entre diferentes setores industriais. Na indústria do cimento, a água é utilizada apenas para resfriamento e nas torres de arrefecimento e toda água utilizada nos processos é liberada em forma de vapor. Enquanto na indústria de Papel e Celulose, que apresenta alta intensidade de uso da água, que vai desde a preparação da matéria-prima até a lavagem da celulose, limpeza, geração de vapor para gerar energia e resfriamento de processos. A maior parte dá água captada é retornada para os rios, sendo $11 \%$ transformada em vapor e $1 \%$ convertida em produtos (OSTRENSKY et al., 2017).

Ainda no tocante do consumo de água pela indústria de transformação de PET avaliada, foram realizados levantamentos do consumo de água com o intuito de traçar um perfil de consumo diário e mensal médio, bem como entender os custos mensais e anuais decorrentes deste consumo de água. De acordo com os resultados expressos na Tabela 3 é possível notar que o consumo de água por hora encontra-se em torno de 1,96 $\mathrm{m}^{3}$ de água, o que acarreta em um consumo diário de $47,04 \mathrm{~m}^{3} \mathrm{e}$, por conseguinte, uma média mensal de consumo em torno de $1411,20 \mathrm{~m}^{3}$ de água. Esses valores geram um custo mensal em torno de $\mathrm{R} \$$ $22.903,78$.

Tabela 3: Perfil do consumo de água na indústria de transformação PET avaliada.

\begin{tabular}{|c|c|c|c|c|c|c|c|}
\hline Mês/Ano & $\begin{array}{l}\text { Consumo } \\
\text { total/horas } \\
\text { avaliadas } \\
\left(\mathrm{m}^{3}\right)\end{array}$ & $\begin{array}{l}\text { Horas } \\
\text { avaliadas }\end{array}$ & $\begin{array}{l}\text { Cons/Hora } \\
\left(\mathrm{m}^{3}\right)\end{array}$ & $\begin{array}{l}\text { Cons/Dia } \\
\left(\mathrm{m}^{3}\right)\end{array}$ & $\begin{array}{l}\text { Cons/ } \\
\text { Mês } \\
\left(\mathrm{m}^{3}\right)\end{array}$ & $\begin{array}{l}\text { Estimativa de } \\
\text { custo mensal } \\
(\mathrm{R} \$)\end{array}$ & $\begin{array}{l}\text { Estimativa } \text { de } \\
\text { custo } \\
\text { (R\$) }\end{array}$ \\
\hline jan/15 & 112,12 & 62,37 & 1,80 & 46,46 & 1393,93 & 22484,11 & 269809,29 \\
\hline $\mathrm{mar} / 15$ & 278,2 & 153,34 & 1,81 & 42,78 & 1283,48 & 20702,55 & 248430,65 \\
\hline$a b r / 15$ & 199,82 & 108,00 & 1,85 & 38,62 & 1158,62 & 18688,52 & 224262,25 \\
\hline jun/15 & 348,84 & 185,14 & 1,88 & 40,54 & 1216,28 & 19618,53 & 235422,41 \\
\hline jul/15 & 372,28 & 192,00 & 1,94 & 40,33 & 1209,84 & 19514,68 & 234176,15 \\
\hline ago/17 & 389,89 & 167,83 & 2,32 & 35,75 & 1072,61 & 17301,26 & 207615,07 \\
\hline out/17 & 522,33 & 233,83 & 2,23 & 33,31 & 999,35 & 16119,53 & 193434,39 \\
\hline nov/17 & 1251,68 & 504,00 & 2,48 & 37,41 & 1122,40 & 18104,31 & 217251,74 \\
\hline $\mathrm{fev} / 18$ & 2559,62 & 1464,00 & 1,75 & 34,36 & 1030,93 & 16628,91 & 199546,86 \\
\hline $\mathrm{mar} / 18$ & 267,15 & 171,50 & 1,56 & 31,52 & 945,51 & 15251,12 & 183013,42 \\
\hline MÉDIA & 630,19 & 324,20 & 1,96 & 47,04 & 1411,20 & $22.621,54$ & $271.458,48$ \\
\hline
\end{tabular}

Baseado nos dados de consumo (tabela 3), verifica-se que a amplitude de abatimento, ou seja, a diferença entre consumo máximo e o mínimo observado é da ordem de 448,43 $\mathrm{m}^{3}$ de água. Essa variação é justificada pela existência de meses em que é realizada a lavagem do sistema, que consiste no esvaziamento de todas as tubulações, sistemas de máquina e equipamentos, torre de resfriamento seguido pela limpeza 
da mesma, a realização deste tipo de procedimento ocasiona em um acréscimo da ordem de $\mathrm{R} \$ 7.278,02$ no mês em que é realizado.

Essa informação é de suma importância, pois quando associada à precipitação na região é capaz de fornecer indicações do mês mais adequado para a realização da lavagem do sistema, e dessa forma minimizar custos de consumo de água potável. Quando se fala de valores de custo anual, estima-se que o valor médio se encontra próximo a $\mathrm{R} \$ 274.800,00$ ao ano. De acordo com a Agência Nacional de Água - ANA (2010), a cobrança deve ser vista como um estímulo ao uso racional da água, pois em função das condições de escassez em quantidade e qualidade, a água deixou de ser um bem totalmente livre e passou a ter valor econômico agregado, uma vez que é primordial para o desenvolvimento humano.

A cobrança pela água tratada utiliza-se como subsídio interno o valor cobrado pela água potável (REBOUÇAS, 2015), e quem consome até $10 \mathrm{~m}^{3} / \mathrm{mês}$. Já quem consome acima são colocados na categoria de consumidores comercial e industrial, e por conta desse consumo mensal, pagarão pelo restante da tarifa. Também existem diferenciação nos valores cobrados pela água potável baseado em particularidades locais e regionais, como escassez de água, relevo, formações litológicas, políticas econômicas entre outras.

Ainda de acordo com ANA, estima-se que as demandas de água para o ano de 2025, cerca de 43 dos 92 municípios do estado do Rio de Janeiro necessitarão de investimentos para garantia da oferta de água, e o custo destes investimentos representarão mais de 1 bilhão de reais e passam por diferentes soluções como novos sistemas conectados, adoção de novos mananciais e adequações de sistemas já existentes.

Nessa perspectiva, Both et al. (2017) defendem que uma indústria que busca entender seu processo produtivo e as demandas de insumos, como a água. E a partir desses resultados optam por adotar estratégias que minimizem tal consumo, contribuem não somente para a minimização de custos dentro do empreendimento, mas também com a garantia de abastecimento de água para diversas famílias, por deixar de consumir dada quantidade de água. Ao mesmo tempo em que servem de exemplo para outros empreendimentos, pois se cada investidor entender todos os benefícios atrelados ao aproveitamento e reúso de insumos a sociedade se torna mais consciente das necessidades ambientais.

\section{Precipitação na Região}

A ideia de utilização das águas pluviais é vista por Fendrich et al. (2002), como uma ação de responsabilidade internacional, uma vez que o desenvolvimento sustentável das cidades está preconizado nas estratégias descritas pela Agenda do Século 21. A Tabela 4 descreve o perfil de chuva na Região do Cabo de Santo Agostinho, local de implantação da indústria, dos anos de 2004 até 2017.

Baseado no histórico foi possível traçar um perfil de precipitação mensal ao longo da série histórica, para que dessa forma se possa planejar o dimensionamento do SAAP, bem como estabelecer as metas e custos mensais de consumo de água. Também é importante saber que o clima do município de Cabo de Santo Agostinho foi caracterizado como tropical, quente e úmido Köppen, com chuvas de outono-inverno, amenizado por brisas marinhas e alísios do Sudeste. A temperatura na região varia de entre 26 e $30^{\circ} \mathrm{C}$, com média anual de $28^{\circ} \mathrm{C}$., com umidade relativa do ar em torno de $80 \%$ (APAC, 2016). 
Tabela 4: Perfil Pluviométrico da Região do Cabo de Santo Agostinho de 2004-2017.

\begin{tabular}{|c|c|c|c|c|c|c|c|c|c|c|c|c|c|c|c|}
\hline COD & POSTO & ANO & JAN & FEV & MAR & $A B R$ & MAI & JUN & JUL & AGO & SET & OUT & NOV & DEZ & MÉDIA \\
\hline 491 & Cabo & 2004 & 311 & 202,4 & 243,7 & 278,8 & 323,8 & 469,8 & 433,8 & 228,1 & 148,9 & 19,4 & 14,2 & 15 & 2688,9 \\
\hline 491 & Cabo & 2005 & 1,2 & 52,2 & 121,8 & 168,1 & 422,4 & 677,1 & 146,7 & 293,9 & 15 & 48,4 & 9,2 & 218,2 & 2174,2 \\
\hline 491 & Cabo & 2006 & 33,8 & 41,8 & 70 & 172,2 & 378,6 & 362,9 & 191,1 & 113 & 67,7 & 8,6 & 42,8 & 70,6 & 1553,1 \\
\hline 491 & Cabo & 2007 & 143,1 & 165 & 188,6 & 313 & 206,8 & 447,5 & 258,3 & 211,7 & 121,8 & 28,8 & 16 & 48,7 & 2149,3 \\
\hline 491 & Cabo & 2008 & 62,4 & 22,4 & 455,8 & 174,8 & 451,8 & 270,5 & 258,9 & 295,7 & 56,7 & 88,2 & 10,8 & 31,2 & 2179,2 \\
\hline 491 & Cabo & 2009 & 167,2 & 174,6 & 175,6 & 359,9 & 295,1 & 385,3 & 266,9 & 146,2 & 64,6 & 16,8 & 22,5 & 25 & 2099,7 \\
\hline 491 & Cabo & 2010 & 120,5 & 50,1 & 78 & 265,7 & 126,2 & 642,7 & 173,4 & 133,3 & 57,2 & 77,2 & 13,5 & 10,2 & 1748 \\
\hline 491 & Cabo & 2011 & 175 & 164,5 & 61,4 & 442,4 & 600,8 & 220 & 499,6 & 113 & 54,8 & 32,4 & 80,4 & 7 & 2451,3 \\
\hline 491 & Cabo & 2012 & 183,8 & 91,4 & 48,6 & 49,9 & 134,6 & 317,6 & 283,4 & 98,2 & 10 & 52,8 & 7,8 & 37,8 & 1315,9 \\
\hline 491 & Cabo & 2013 & 54,6 & 9,6 & 133,8 & 196,7 & 205,9 & 326,3 & 402 & 209 & 153,6 & 118,6 & 53 & 49 & 1912,1 \\
\hline 491 & Cabo & 2014 & 101,8 & 225,8 & 141,9 & 338,1 & 278,8 & 322,7 & 131,7 & 189 & 177,6 & 217,4 & 22,9 & 49,3 & 2197 \\
\hline 491 & Cabo & 2015 & 68 & 73,4 & 302,8 & 20,9 & 154,7 & 420,4 & 485,4 & 133,5 & 42,6 & 29,7 & 6,7 & 72,9 & 1811 \\
\hline 491 & Cabo & 2016 & 135,7 & 48,4 & 248,2 & 219,8 & 291,7 & 114,3 & 114,6 & 42 & 35,9 & 22,8 & 5,7 & 15,9 & 1295 \\
\hline 491 & Cabo & 2017 & 21,6 & 20,6 & 143,4 & 200,8 & 500,3 & 394,4 & 565,3 & 160,7 & 91 & 34 & 9,7 & 42,4 & 2184,2 \\
\hline \multicolumn{3}{|c|}{ MÉDIA MENSAL } & 112,8 & 95,9 & 172,7 & 228,6 & 312,2 & 383,7 & 300,8 & 169,1 & 78,4 & 56,8 & 22,5 & 49,5 & 1982,8 \\
\hline
\end{tabular}

Silva et al. (2012) explanam que os grandes eventos pluviais refletem nas atividades humanas, pois são capazes de causar alagamentos, cheias, enchentes, inundações, movimentos de massa, perdas das lavouras, destruição da infraestrutura que acarretam em prejuízos financeiros e até mesmo mortes. Desta forma, o conhecimento dos limites máximos de chuvas é essencial para dimensionar a capacidade de suporte e estruturas de contenção existentes, afim de evitar além de problemas como o assoreamento em reservatórios de armazenamento de água para os sistemas de aproveitamento de águas pluviais deste empreendimento (SOUSA et al., 2016).

De acordo com o perfil pluviométrico da região observa-se que o mês de junho apresenta a maior média pluviométrica ao longo do ano, cerca de $383,7 \mathrm{~mm}$ (tabela 4). Por outro lado, o mês de novembro apresenta uma média de $22,5 \mathrm{~mm}$. A partir destes dados são delimitadas as informações para o dimensionamento do reservatório, bem como o planejamento orçamentário ao longo do ano.

Alguns autores demonstraram em seu trabalho as precipitações mensais na região, entre os anos de 2001 e 2004 e constataram que as chuvas estavam concentradas entre os meses de abril a julho, com médias mensais variando entre $77 \mathrm{~mm}$ a $660 \mathrm{~mm}$. Os autores discutem que o período de agosto a março é considerado de baixa precipitação pluviométrica. A partir do histórico médio de precipitação anual na região do Cabo de Santo Agostinho é possível entender a contribuição volumétrica de chuva dos meses ao longo do ano (Figura 3).

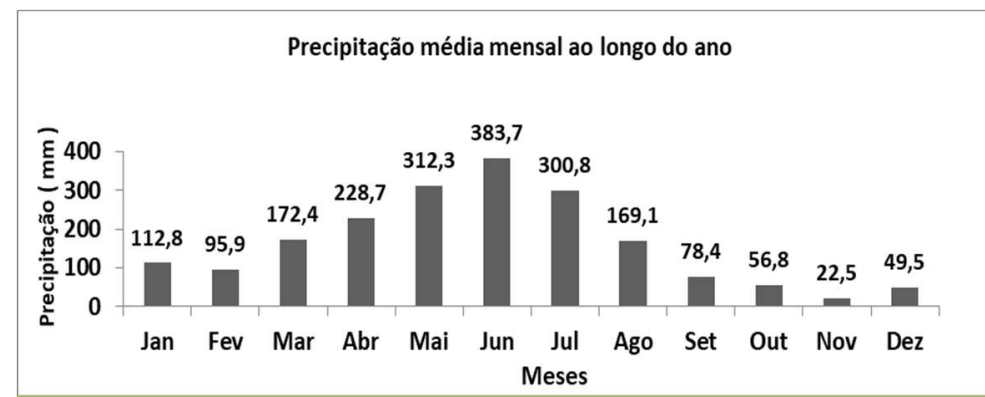

Figura 3: Distribuição pluviométrica na região do Cabo de Santo Agostinho entre 2004-2017.

Nota-se que o volume de chuva produzido entre os meses de janeiro e julho são responsáveis por $81,02 \%$ da pluviosidade na região. Da mesma forma, ao considerar a pluviosidade do período entre janeiro e setembro constatou-se que este período é responsável por 93,50\% do volume pluviométrico anual. A partir 
da perspectiva apresentada, é possível inferir que o período entre janeiro e setembro será primordial para o abastecimento do sistema de captação proposto. Por outro lado, os meses de outubro a dezembro correspondem a 6,50\% da pluviosidade anual, indicando a necessidade de entender previamente que há possibilidade de menor potencial de coleta de água da chuva para o sistema de reaproveitamento.

\section{Qualidade da Água}

A água captada pelo sistema é utilizada para fins não potáveis, pois a água pluvial, dependendo do local onde é captada, devido à poluição local, não é apropriada para o consumo humano, uma vez que para seu consumo devem ser realizadas outras análises físico-químicas e microbiológicas, como turbidez, cor, dureza, amônia, coliformes e outros. Dentre os parâmetros que mais interferem em um sistema de irrigação o destaque vai para os parâmetros químicos (ALVES et al., 2016), pois estes estão diretamente ligados à obstrução física das tubulações e emissores devido a alguns íons sofrerem reações de precipitação ou oxidação, ou mesmo a deposição de partículas minerais, como silte e argila, aumentando, assim, a perda de carga e diminuindo a vida útil do sistema

$\mathrm{Na}$ indústria de transformação de plástico, moldagem por injeção, especificamente na manufatura de pré-formas em PET, os cuidados e monitoramentos com a qualidade da água é de suma importância. Isso se dar em primeiro lugar porque as máquinas e equipamentos nos quais são utilizados essas águas, são composto de materiais e polímeros com metalurgias diversas e por esses motivos não é especialmente verdadeiro generalizar e de forma superficial que uma determinada água seja boa ou ruim para utilização nesses sistemas, e, por mais que se considere uma água de boa qualidade, isso não dispensa a adição de produtos químicos na água para manutenção do seu padrão de qualidade que seja adequada a esse processo. A exemplo disso é quando se usa água potável nesse processo, mesmo assim não isenta da adição de produtos químicos.

De acordo com os resultados da análise da água da chuva na região do Cabo de Santo Agostinho é possível concluir que todas as variáveis se encontram dentro dos intervalos de potabilidade, sendo inclusive indicadas para o consumo humano, se incorporados outros agente que compõem os critérios de potabilidade para consumo humano, segundo as legislações vigentes (Tabela 5).

A partir dos dados de alcalinidade e pH é possível notar que a água da região se encontra com o pH potencialmente neutro (próximo de 7), e isto contribui para sua viabilidade industrial, visto que tornar a água básica é uma das primeiras etapas do tratamento de água para fins industriais. Parron et al. (2011) afirmam que em águas naturais, as medidas de pH e alcalinidade são determinantes para o estudo de produtividade biológica, pois estas características são primordiais para o desenvolvimento de organismos. Com relação a variação de pH, a água ainda pode possuir capacidade tampão, e por conta disso, é capaz de neutralizar ácidos não deixando que o $\mathrm{pH}$ se altere.

Tanto a cor aparente da água, quanto a turbidez são variáveis relacionadas a qualidade estética da água, e a partir da tabela 5 nota-se que a amostra analisada possuía baixa quantidade de sólidos dissolvidos o que acarretou em baixos valores de cor aparente e turbidez, indicando aspectos positivos de qualidade da 
água. As demais variáveis encontram-se em equilíbrio químico justificado, principalmente, pelo valor neutro do $\mathrm{pH}$.

Tabela 5: Resultado da análise físico-química da água da chuva coletada na região do Cabo de Santo Agostinho-PE.

\begin{tabular}{|c|c|c|c|}
\hline Parâmetros & Valores encontrados & Valores máximos & Unidade \\
\hline Amônia como $\mathrm{NH}_{3}$ & $<0,06$ & 1,5 & $\mathrm{mgL}^{-1}$ \\
\hline Cloreto & 4,98 & 250 & $\mathrm{mgL}^{-1}$ \\
\hline Cor Aparente & 5,2 & 500 & $\mathrm{uH}^{-1}$ \\
\hline Dureza & 17,04 & 0,3 & $\mathrm{mgL}^{-1}$ \\
\hline Ferro & $<0,05$ & 0,1 & $\mathrm{mgL}^{-1}$ \\
\hline Manganês & $\mathrm{ND}$ & 200 & $\mathrm{mgL}^{-1}$ \\
\hline Sódio & 2,1 & 200 & $\mathrm{mgL}^{-1}$ \\
\hline Sulfato & 0,58 & 5 & $\mathrm{mgL}^{-1}$ \\
\hline Turbidez & 0,66 & 5 & $\mathrm{uT}^{-1}$ \\
\hline Zinco & 0,02 & - & $\mathrm{mgL}^{-1}$ \\
\hline Alcalinidade de Bicarbonatos & 16 & 500 & $\mathrm{mgL}^{-1}$ \\
\hline Dureza Total & 17,04 & $\mathrm{mgL}^{-1}$ \\
\hline pH & 7,5 & recomendável de 6 a 9,5 & - \\
\hline
\end{tabular}

No que tange ao uso de água no caso citado a adoção de cuidados com a qualidade da água são constantemente avaliados para evitar incrustação no sistema que se usam água para resfriamento (água geralmente utilizada em temperatura ambiente, em torres de resfriamento e trocadores de calor e outros). Normalmente para esse tipo de processo, tem como predominantemente tubulações a base de aço carbono, metalurgias dos equipamentos geralmente são a base aço carbono e cobre, e, utilizam-se produtos químicos a base de fosfato, além de um bom controle de drenagem constante de controlado das torres de resfriamento, buscando evitar que devido ao ciclo de concentração a dureza da água venha aumentar ao longo do uso, potencializando assim, incrustações nas tubulações, orifícios e capilares dos equipamentos que compõem o processo de produção. Geralmente, quando a água contém menos de 100 ppm de $\mathrm{CaCO}_{3}$, ela é considerada como 'mole'; até 270 ppm, 'semidura'; menos de 360 ppm, 'dura' e acima de 470 ppm, 'muito dura'. Estes sais formam a chamada 'pedra de leite' (GUERRA et al., 2011), sendo necessário para sua eliminação, o uso de detergentes ácidos em maior frequência e concentração. Isso eleva os custos de produção, pois a água dura diminui as concentrações ideais dos princípios ativos das soluções, interferindo, portanto, nas suas propriedades. Além do cálcio, outros elementos como ferro, zinco, alumínio e manganês podem contribuir para a dureza da água e serem tóxicos quando em altas concentrações

Outro fato importante desta necessidade de avaliação é para evitar corrosão nos sistemas que utilizam água de refrigeração (água normalmente utilizada em temperaturas entre $4^{\circ}$ e $8^{\circ} \mathrm{C}$, em moldes, placas de cavidades e placas de robô e outros). Normalmente para esse tipo de processo, tem predominância adotar tubulações em aço inox e as metalurgias dos equipamentos normalmente se predomina aço inox e alumínio, e, utilizam-se produtos químicos a base de nitrito, pois de o nitrito tem o poder de atuar formando uma fina película de passivação nas paredes internas do sistema, impedindo assim potencializar um processo corrosivo.

\section{Custo de implantação}

Para o cálculo do custo de implantação do SAAP foram utilizados orçamentos de três empresas 
distintas consideradas de boa capacidade técnica (Pequena, Médio e Grande porte) e dentre elas optaramse por aquela com preço intermediário. Os orçamentos incluem os valores para a implementação de um sistema de captação de águas pluviais, a confecção de cisternas com capacidade de $10.587 \mathrm{~m}^{3}, 999,0 \mathrm{~m}^{3}$, $505,0 \mathrm{~m}^{3}, 500,0 \mathrm{~m}^{3}, 466,0 \mathrm{~m}^{3}, 462,0 \mathrm{~m}^{3}, 427,0 \mathrm{~m}^{3}, 400,0 \mathrm{~m}^{3}, 396,58 \mathrm{~m}^{3}, 391,0 \mathrm{~m}^{3}, 390,0 \mathrm{~m}^{3}, 380,72 \mathrm{~m}^{3}, 362,0$ $\mathrm{m}^{3}, 300,0 \mathrm{~m}^{3}, 250,0 \mathrm{~m}^{3}, 203,0 \mathrm{~m}^{3}, 200,0 \mathrm{~m}^{3}, 145,0 \mathrm{~m}^{3}, 100,0 \mathrm{~m}^{3}, 50,0 \mathrm{~m}^{3}, 36,0 \mathrm{~m}^{3}$ e $20 \mathrm{~m}^{3}$, que foram os melhores resultados obtidos nos métodos avaliados.

Tabela 6: Resumo dos volumes e orçamentos dos métodos de dimensionamentos avaliados.

\begin{tabular}{|c|c|c|c|c|c|}
\hline Seq. & Método & $\begin{array}{l}\text { Volume do } \\
\text { sistema } \mathrm{m}^{3}\end{array}$ & $\begin{array}{c}\text { Custo para } \\
\text { implementação do } \\
\text { sistema (R\$) }\end{array}$ & $\begin{array}{c}\text { Custo para } \\
\text { implementação do } \\
\text { sistema (R\$) }\end{array}$ & $\begin{array}{c}\text { Custo para } \\
\text { implementação do } \\
\text { sistema (R\$) }\end{array}$ \\
\hline & & & $\begin{array}{l}\text { Empresa 1- Grande } \\
\text { porte }\end{array}$ & Empresa 2 - Médio porte & $\begin{array}{c}\text { Empresa } 3 \text { Pequeno } \\
\text { porte }\end{array}$ \\
\hline 1 & Rippl & $10.587,00$ & $\mathrm{R} \$ 6.892 .137,00$ & $R \$ 5.907 .546,00$ & $\mathrm{R} \$ 5.316 .791,40$ \\
\hline 2 & Azevedo Neto & 999 & $\mathrm{R} \$ 650.349,00$ & $\mathrm{R} \$ 557.442,00$ & $\mathrm{R} \$ 501.697,80$ \\
\hline 3 & Rippl & 505 & $\mathrm{R} \$ 328.755,00$ & $\mathrm{R} \$ 281.790,00$ & $\mathrm{R} \$ 253.611,00$ \\
\hline 4 & Prático Australiano & 500 & $R \$ 325.500,00$ & $\mathrm{R} \$ 279.000,00$ & $R \$ 251.100,00$ \\
\hline 5 & Simulação & 466 & $\mathrm{R} \$ 303.366,00$ & $\mathrm{R} \$ 260.028,00$ & $\mathrm{R} \$ 234.025,20$ \\
\hline 6 & Prático Australiano & 491,5 & $\mathrm{R} \$ 319.966,50$ & $\mathrm{R} \$ 274.257,00$ & $\mathrm{R} \$ 246.831,30$ \\
\hline 7 & Prático Australiano & 427 & $\mathrm{R} \$ 277.977,00$ & $\mathrm{R} \$ 238.266,00$ & $\mathrm{R} \$ 214.439,40$ \\
\hline 8 & Prático Australiano & 400 & $\mathrm{R} \$ 260.400,00$ & $\mathrm{R} \$ 223.200,00$ & $\mathrm{R} \$ 200.880,00$ \\
\hline 9 & Prático Inglês & 396,6 & $\mathrm{R} \$ 258.186,60$ & $\mathrm{R} \$ 221.302,80$ & $\mathrm{R} \$ 199.172,52$ \\
\hline 10 & Simulação & 390 & $\mathrm{R} \$ 253.890,00$ & $\mathrm{R} \$ 217.620,00$ & $\mathrm{R} \$ 195.858,00$ \\
\hline 11 & Prático Alemão & 380,7 & $\mathrm{R} \$ 247.835,70$ & $\mathrm{R} \$ 212.430,60$ & $\mathrm{R} \$ 191.187,54$ \\
\hline 12 & Prático Australiano & 362 & $\mathrm{R} \$ 235.662,00$ & $\mathrm{R} \$ 201.996,00$ & $\mathrm{R} \$ 181.796,40$ \\
\hline 13 & Prático Australiano & 300 & $\mathrm{R} \$ 195.300,00$ & $\mathrm{R} \$ 167.400,00$ & $\mathrm{R} \$ 150.660,00$ \\
\hline 14 & Simulação & 300 & $\mathrm{R} \$ 195.300,00$ & $\mathrm{R} \$ 167.400,00$ & $\mathrm{R} \$ 150.660,00$ \\
\hline 15 & Simulação & 250 & $\mathrm{R} \$ 162.750,00$ & $R \$ 139.500,00$ & $\mathrm{R} \$ 125.550,00$ \\
\hline 16 & Prático Alemão & 203 & $\mathrm{R} \$ 132.153,00$ & $\mathrm{R} \$ 113.274,00$ & $\mathrm{R} \$ 101.946,60$ \\
\hline 17 & Simulação & 200 & $\mathrm{R} \$ 130.200,00$ & $\mathrm{R} \$ 111.600,00$ & $\mathrm{R} \$ 100.440,00$ \\
\hline 18 & Prático Australiano & 145 & $\mathrm{R} \$ 94.395,00$ & $\mathrm{R} \$ 80.910,00$ & $\mathrm{R} \$ 72.819,00$ \\
\hline 19 & Prático Australiano & 100 & $\mathrm{R} \$ 65.100,00$ & $\mathrm{R} \$ 55.800,00$ & $\mathrm{R} \$ 50.220,00$ \\
\hline 20 & Prático Australiano & 50 & $\mathrm{R} \$ 32.550,00$ & $\mathrm{R} \$ 27.900,00$ & $\mathrm{R} \$ 25.110,00$ \\
\hline 21 & Prático Australiano & 36 & $\mathrm{R} \$ 23.436,00$ & $\mathrm{R} \$ 20.088,00$ & $\mathrm{R} \$ 18.079,20$ \\
\hline 22 & Prático Australiano & 20 & $\mathrm{R} \$ 13.020,00$ & $\mathrm{R} \$ 11.160,00$ & $\mathrm{R} \$ 10.044,00$ \\
\hline 23 & Programa Netuno & 600 & $\mathrm{R} \$ 390.600,00$ & $\mathrm{R} \$ 334.800,00$ & $\mathrm{R} \$ 301.320,00$ \\
\hline 24 & Programa Netuno & 550 & $\mathrm{R} \$ 358.050,00$ & $\mathrm{R} \$ 306.900,00$ & $R \$ 276.210,00$ \\
\hline 25 & Programa Netuno & 500 & $\mathrm{R} \$ 325.500,00$ & $\mathrm{R} \$ 279.000,00$ & $\mathrm{R} \$ 251.100,00$ \\
\hline 26 & Programa Netuno & 450 & $\mathrm{R} \$ 292.950,00$ & $\mathrm{R} \$ 251.100,00$ & $\mathrm{R} \$ 225.990,00$ \\
\hline 27 & Programa Netuno & 400 & $\mathrm{R} \$ 260.400,00$ & $R \$ 223.200,00$ & $\mathrm{R} \$ 200.880,00$ \\
\hline 28 & Programa Netuno & 350 & $\mathrm{R} \$ 227.850,00$ & $\mathrm{R} \$ 195.300,00$ & $\mathrm{R} \$ 175.770,00$ \\
\hline 29 & Programa Netuno & 300 & $\mathrm{R} \$ 195.300,00$ & $\mathrm{R} \$ 167.400,00$ & $\mathrm{R} \$ 150.660,00$ \\
\hline 30 & Programa Netuno & 250 & $\mathrm{R} \$ 162.750,00$ & $\mathrm{R} \$ 139.500,00$ & $\mathrm{R} \$ 125.550,00$ \\
\hline 31 & Programa Netuno & 200 & $\mathrm{R} \$ 130.200,00$ & $\mathrm{R} \$ 111.600,00$ & $\mathrm{R} \$ 100.440,00$ \\
\hline 32 & Programa Netuno & 150 & $\mathrm{R} \$ 97.650,00$ & $\mathrm{R} \$ 83.700,00$ & $\mathrm{R} \$ 75.330,00$ \\
\hline 33 & Programa Netuno & 100 & $\mathrm{R} \$ 65.100,00$ & $\mathrm{R} \$ 55.800,00$ & $\mathrm{R} \$ 50.220,00$ \\
\hline 34 & Programa Netuno & 50 & $\mathrm{R} \$ 32.550,00$ & $\mathrm{R} \$ 27.900,00$ & $\mathrm{R} \$ 25.110,00$ \\
\hline
\end{tabular}

Obs.: Microempresa = receita anual $\leq \mathrm{R} \$ 360 \mathrm{mil}$; Pequena empresa = receita anual $>\mathrm{R} \$ 360 \mathrm{mil}$ e $\leq \mathrm{R} \$ 4.8 \mathrm{milhões}$; Média empresa $=$ receita anual $>\mathrm{R} \$ 4.8$ milhões e $\leq \mathrm{R} \$ 300$ milhões; Grande empresa $=$ receita anual $>\mathrm{R} \$ 300$ milhões (BNDS, 2019).

Nos valores apresentados já estão inclusos mão de obra e todos os materiais necessários desde o projeto até o funcionamento do sistema, incluindo bombas e tubulações, deixando o sistema operando (Tabela 6). A partir da apresentação destes valores, foi possível verificar que o dimensionamento realizado por diferentes métodos apresentou resultados variados. Este fato é justificado, principalmente pela diferença de aplicabilidade metodológica entre os métodos, pois no caso do Prático Australiano, a utilização 
de tamanho de reservatório adequado depende do índice de confiança superior a 90\%. Enquanto o volume é determinado pelo método de Rippl como a soma dos volumes de água coletado nos meses com precipitação superior ao consumo industrial e outros métodos com as suas respectivas particularidades.

Na concepção de Sampaio (2013), os métodos existentes ainda são muito vagos e por vezes, não são aplicáveis a todas as situações, uma vez que usam diferentes parâmetros e diferentes considerações, e embasados a partir de regimes pluviométricos diversos. Por conta destes fatores, há uma grande diferença entre os volumes encontrados em cada método, sendo que o método de Rippl é o mais conservador, gerando resultados bem altos, o que comprometeria muitas vezes a viabilidade econômico-financeira do sistema.

Apesar do superdimensionamento realizado pelo método de Rippl, sua aplicação é justificada pela possibilidade de verificação do limite superior do volume do reservatório de acumulação de águas de chuvas. Contudo, neste estudo os métodos de Rippl e Azevedo Netto não dimensionam reservatórios capazes de retratar a realidade do empreendimento.

Ao contrário da maioria dos estudos de reaproveitamento da água da chuva, a indústria avaliada demanda de uma grande quantidade de água diariamente, por conta disso, a água do reservatório será utilizada diariamente durante o ano. E por conta disso os valores de dimensionamento de SAAP muito elevados não serão viáveis, pois a escolha do melhor dimensionamento depende não apenas da demanda da indústria, mas também da pluviosidade da região.

Portanto, para esse projeto o importante não é suprir toda a demanda com água da chuva, e sim conseguir o maior consumo de água de chuva possível (em torno de $20 \%$ da demanda industrial), diminuindo assim a demanda pela água potável vinda do sistema de abastecimento público, associando a percepção do profissional à demanda industrial proposta.

No que tange ao aspecto financeiro e considerando analogamente que a empresa de grande porte seja a $n^{\circ} 1$, a empresa de médio porte seja a empresa $n^{\circ} 2$ e a empresa de pequeno porte seja a $n^{\circ} 3$ (Tabela 6), observou-se que a diferença de custos da empresa $n^{\circ} 2$ em relação a empresa $n^{\circ} 3$ é da ordem de $10,7 \%$ e da empresa $n^{\circ} 3$ para a empresa $n^{\circ} 1$ é de aproximadamente $30 \%$ e um dos motivos que justifica essa diferença expressiva de custos entre a empresa de grande porte e a de pequeno porte é que a empresa de grande porte apresenta uma estrutura própria mais complexa demanda de mais equipamentos e funcionários e com isso os seus custos se elevam em relação as outras. Portanto a empresa utilizada para as simulações subsequentes é a empresa 2 (médio porte).

\section{Retorno do Investimento}

Baseado nos índices históricos de precipitação para cada mês ao longo do ano foi possível estimar o volume de água esperado para cada mês e, por conseguinte, a redução do consumo de água potável e o custo mensal correspondente a esses valores (Tabela 6). O mês de junho apresenta maior pluviosidade (383,7 $\mathrm{mm}$ ), portanto estima-se que neste mês tenha um maior volume de água pluvial captada o que pode gerar uma maior redução no consumo de água potável, enquanto o mês de novembro, com a menor pluviosidade $(32,40 \mathrm{~mm})$. Estima-se que a captação de água pluvial ao longo do ano seja da ordem de $3.386 \mathrm{~m}^{3}$, que 
corresponde a uma redução de $\$ 14.695,5$.

Tabela 6: Estimativa mensal de redução do consumo de água potável, considerando que fosse possível captar todo o volume de água que a pluviosidade dispõe.

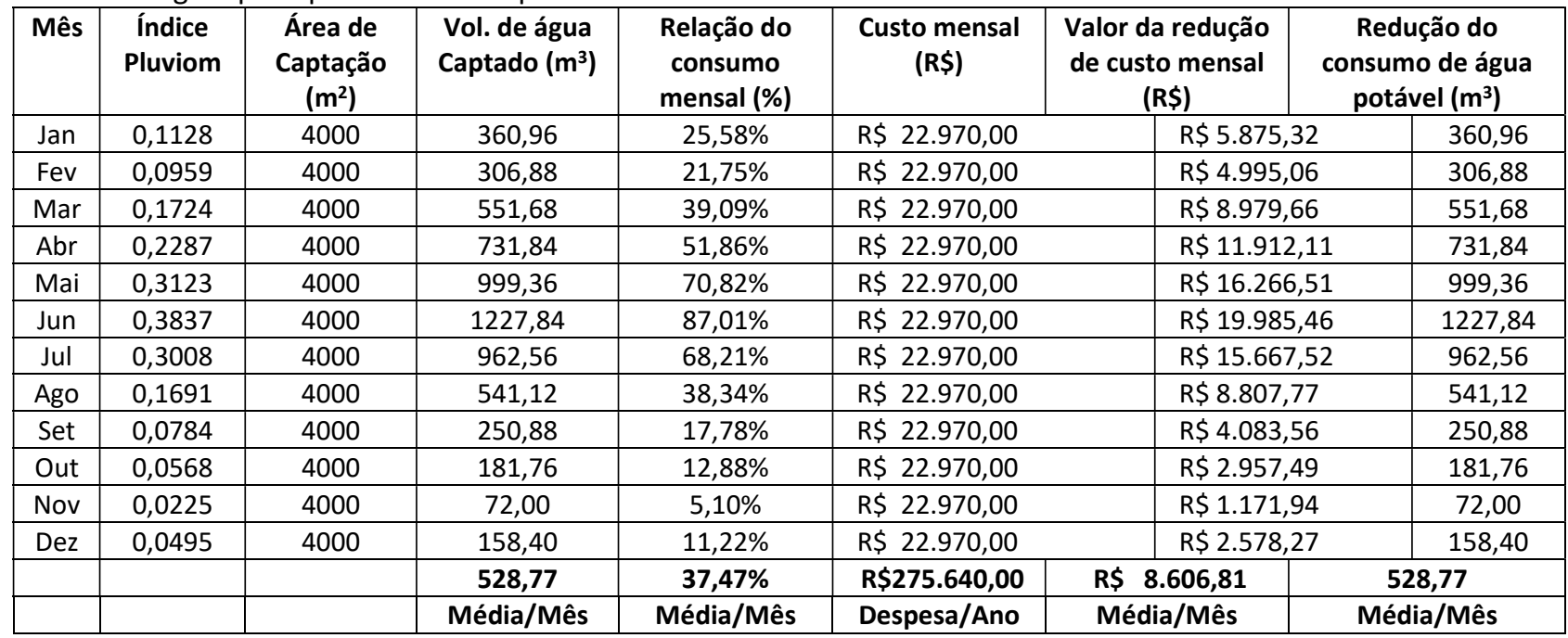

Costa et al. (2015) afirmam que apesar de saberem da importância dos recursos naturais, nem todas as pessoas compreendem que um dos pontos para diminuir o desperdício de água vem da percepção de cada um, com a diminuição do consumo e identificação de sistemas eficientes com o objetivo de melhorar a sobrevivência diante do problema da escassez de água que vivenciamos atualmente, cabe majoritariamente às empresas tomar as providencias necessárias de redução no consumo de água, já que o governo está tomando as providências tardiamente e tendo em vista que essas medidas não serão suficientes para atingir o resultado esperado.

Com a implementação deste sistema de aproveitamento de águas pluviais estima-se uma economia média mensal de $\mathrm{R} \$ 4.580,11$ pois a implantação do SAAP pode contribuir com uma redução média mensal de 20,35 do consumo de água, que justifica uma economia anual de $3.386 \mathrm{~m}^{3}$ de água, que corresponde de $\mathrm{R} \$ 54.961,32$ anuais.

A estratégia utilizada para avaliar a viabilidade deste projeto foi o cálculo do payback. Que consiste em determinar o número de períodos (meses neste estudo) necessários para recuperar o capital investido. Então este método é capaz de avaliar a atratividade de um investimento, todavia não serve para seleção entre possibilidades de investimento (DOMINGOS et al., 2017). Os critérios de avaliação deste trabalho foram o payback, o percentual de demanda avaliado e o percentual de confiança (Tabela 8).

Nota-se que os métodos de dimensionamento que mais se destacam com relação ao percentual de confiança são o método da Simulação e o Prático Australiano, no entanto os métodos Netuno e Alemão se tornaram mais atrativos para o projeto. Enquanto os métodos da Simulação e Australiano indica um volume de reservatório com payback de 56,8 e 51,9 meses respectivamente para um potencial de redução do consumo de água potável da ordem de $20,35 \%$, os métodos Alemão e Netuno sugerem reservatórios dom payback de 24,8 e 29,9 meses para o mesmo potencial de redução do consumo de água potável. 
Tabela 8: Métodos que obedecem ao critério do percentual de confiança.

\begin{tabular}{|c|c|c|c|c|}
\hline Método & $\begin{array}{c}\text { Valor do } \\
\text { reservatório } \\
\text { em } \mathbf{~ m}^{\mathbf{3}}\end{array}$ & $\begin{array}{c}\text { Capacidade \% de } \\
\text { atender a demanda }\end{array}$ & $\begin{array}{c}\text { \% da } \\
\text { demanda } \\
\text { usada no } \\
\text { cálculo }\end{array}$ & Payback (meses) \\
\hline Simulação & 466,0 & 20,0 & 20 & 56,8 \\
\hline Simulação & 250,0 & 15,0 & 15 & 40,7 \\
\hline Prático Australiano & 491,5 & 23,1 & 20 & 51,9 \\
\hline Prático Australiano & 427,0 & 20,0 & 20 & 48,7 \\
\hline Prático Australiano & 400,0 & 18,7 & 20 & 52,0 \\
\hline Prático Australiano & 362,0 & 16,9 & 20 & $91,7 \%$ \\
\hline Programa Netuno & 250,0 & 20,3 & 30 & $51,7 \%$ \\
\hline Prático Alemão & 203,2 & 20,0 & 20 & 29,1 \\
\hline
\end{tabular}

O critério econômico é determinante para a tomada de decisões no âmbito comercial, por conta disso, o método que apresentar evidências de atendimento da demanda proposta e o menor payback é aquele capaz de promover o retorno do investimento em menos tempo. De acordo com a tabela 19, a diferença de investimento entre as duas possibilidades Netuno e Alemão é desprezível e com uma margem de segurança se opta pela opção do Netuno pela garantia demostrada de atendimento de $20,35 \%$ da demanda total de água na com um retorno financeiro em 29,9 meses. Vale ressaltar que os métodos da Simulação $466 \mathrm{~m}^{3}$ e Australiano 491,5 $\mathrm{m}^{3}$, também atenderia a redução proposta no projeto, no entanto com um payback muito maior o que tornaria o projeto a apesar de financeiramente ainda viável, porém menos atrativo.

Os resultados encontrados demonstram compatibilidade com a região e com o objetivo proposto, além disso, Rezende et al. (2017) defendem que o dimensionamento adequado do reservatório de armazenamento é primordial para garantir a viabilidade técnica e econômica de um sistema de aproveitamento de água de chuva. E um sistema adequado deve ser capaz de atender a maior demanda possível com o menor custo, pois reservatórios demasiadamente grandes podem ser inviáveis tanto física quanto economicamente, promovendo a baixa ociosidade e a diminuição do desperdício de água pluvial em detrimento ao atendimento da demanda necessária.

\section{Tomada de Decisão}

Diante dos resultados apresentados, segundo os 06 métodos aplicado segundo a ABNT NBR 5527:2007 e a simulação realizada pelo programa computacional Netuno é possível constatar a viabilidade do projeto. Para tanto se observou possibilidades viáveis para a implementação do projeto quando levado em consideração a relação custos de implementação e payback, uma através do método prático Alemão e outra sugerida pelo método do programa computacional Netuno, no entanto entre essas opções a mais adequada é a opção do método Netuno, por fornecer uma maior relação de segurança na relação volume do reservatório, potencial de economia de água potável e payback. Portanto como definição, considera-se: Reservatório com capacidade de $250 \mathrm{~m}^{3}$, com potencial de captação de água pluvial da ordem de $20,0 \%$ da demanda total, com uma economia estimada em \$14.695,5 por ano e com payback de 30 meses. 


\section{CONCLUSÕES}

É sabido que o consumo de água pelas indústrias é bem maior que o consumo doméstico e estratégias de aproveitamento de águas pluviais pode promover a minimização do consumo médio de água potável. Nesta perspectiva é possível concluir que: A demanda hídrica da indústria avaliada apresenta uma média diária de consumo igual a 47, $04 \mathrm{~m}^{3}$; A água da chuva coletada na região do Cabo de Santo Agostinho atende as especificações de potabilidade, sendo adequada para a utilização não potável na indústria avaliada; A implantação deste sistema pode promover uma economia de água torno de 3.386 litros de água anual, que corresponde a $\$ 14.695,5$ anuais, equivalente a uma redução de $20 \%$ do consumo de água potável; Ao optar pela implantação de um SAAP de $250 \mathrm{~m}^{3}$ será demandado um investimento de $\mathrm{R} \$ 139.500,00$ ou $\$ 37.299$, cujo retorno financeiro ocorrerá após 30 meses. Desta forma a implantação deste sistema apresenta viabilidade econômica e apresenta benefícios ambientais significativos, contribuindo para a sustentabilidade ambiental, visando atender as necessidades da geração presente sem comprometer o atendimento das futuras gerações.

\section{REFERÊNCIAS}

ABNT. Associação Brasileira de Normas Técnicas. NBR 15527: Água de chuva: Aproveitamento de coberturas em áreas urbanas para fins não potáveis: Requisitos. Rio de Janeiro: ABNT, 2007.

APAC. Agência Pernambucana de Águas e Clima. Boletim do Clima Síntese Climática: Síntese Climática. Recife: APAC, 2016.

ALVES, D. V.; NUNES, J. S.; FARIA, L. P. P.. Aplicabilidade do aproveitamento de águas pluviais em grandes centros urbanos: estudo de caso aplicado a uma residência de Belo Horizonte (MG). Revista Petra, v.2, n.2, 2016.

AMORIM, L. M. M. F.; SOUZA, T. M.. Análise da viabilidade do aproveitamento de água pluvial para fins não potáveis de um clube recreativo, na cidade de Maringá/PR. Revista Unigá Review, Maringá, v.28, n.2, 2016.

BOTH, F.; FISCHER, A.. Gestão e contabilidade ambiental. Unoesc \& Ciência: ACSA, v.8, n.1, p.49-58, 2017.

COSTA, J. O.; ESTENDER, A. C.. A percepção do desperdício da água com a utilização da água de reúso. Revista Desafios, v.2, n.1, p.109-126, 2015. DOI:

https://doi.org/10.20873/uft.2359-3652.2015v2n1p109

DOMINGOS, B. D. S.; MOREIRA, C. R.; RESENDE, É. W.; RODRIGUES, D. M. S.; DORNELAS, J. D. O.. Estudo de payback simples para a substituição do gás liquefeito de petróleo pelo biogás em uma unidade hospitalar em Minas Gerais. In: SIMPROD, 9. Anais. 2017.

DONATO, L. A.; BARBOSA, M. F. N.; BARBOSA, E. M.. Reciclagem: o caminho para o desenvolvimento sustentável. Polêmica, v.15, n.2, p.023-034, 2015. DOI: https://doi.org/10.12957/polemica.2015.17838

DUARTE, G. W.; MATTOS, A. S.; EING, C.; SILVA, D. L.;
FRASSON, K. C.; ECKERT, C. L.. Aproveitamento de água pluvial para fins não potáveis: estudo de caso na jardinagem. Revista Ciência \& Cidadania, v.1, n.1, 2015.

FENDRICH, R.. Coleta, Armazenamento, Utilização e Infiltração das Águas Pluviais na Drenagem Urbana. Tese (Doutorado em Geologia Ambiental) - Universidade federal do Paraná, Curitiba, 2002.

FUNASA. Fundação Nacional de Saúde. Manual prático de análise de água. 4 ed. Brasília: FUNASA, 2013.

GUERRA, M. G.; JÚNIOR, J. G. B. G.; RANGEL, A. H. N.; ARAÚJO, V. M.; GUILHERMINO, M. M.; NOVAES, L. P.. Disponibilidade e qualidade da água na produção de leite. Acta Veterinária Brasílica, v.5, n.3, p.230-235, 2011. DOI: https://doi.org/10.21708/avb.2011.5.3.2308

OSTRENSKY, V. P.; GARCIA, J. R.. A cobrança pelo uso da água na Região Metropolitana de Curitiba: uma análise dos impactos econômicos no setor industrial. Revista da FAE, v.20, n.2, p.7-20, 2017.

PADILLA, C. P.; ARÉVALO, D. X.; BUSTAMANTE, M. A.; VIDAL, C. L.. Responsabilidad Social Empresarial y desempeño financiero en la industria del plástico em ecuador. Información tecnológica, v.28, n.4, p.93-102, 2017. DOI: http://doi.org/10.4067/S0718-07642017000400012

PARRON, L. M.; MUNIZ, H. F.; PEREIRA, C. M.. Manual de procedimentos de amostragem e análise físico-química de água. Brasília: Embrapa Florestas, 2011.

REBOUÇAS, A.. Uso inteligente da água. Escrituras Editora e Distribuidora de Livros Ltda., 2015.

REZENDE, J H; TECEDOR, N. Aproveitamento de água de chuva de cobertura em edificações: dimensionamento do reservatório pelos métodos descritos na NBR 
15527. Ambiente \& Água-An Interdisciplinary Journal of Applied Science, v.12, n.6, p.1040-1053, 2017. DOI: http://doi.org/10.4136/ambi-agua.1940

SAMPAIO, F. V.. Análise da viabilidade de implantação e pré-dimensionamento de sistemas de aproveitamento de água pluvial em centros urbanos. Dissertação (Mestrado em Tecnologia Ambiental e Recursos Hídricos) - Universidade de Brasília, Brasília, 2013.

SILVA, A. D. C.; ROCHA, L. V.; MACHADO, A. P.; GUTIERREZ, D. M. G.; SANTOS, L. S.; GUTIERREZ, C. B. B.. Sistema de automação para captação de águas pluviais e gerenciamento hídrico residencial utilizando aplicativo móvel. Sistema, v.38, n.19, 2017.

SOUSA, F. A. S.; VIEIRA, V. R.; SILVA, V. P. R.; MELO, V. S.; GUEDES, R. W. S.. Estimativas dos riscos de chuvas extremas nas capitais do Nordeste do Brasil. Revista Brasileira de Geografia Física, v.9, n.2, p.430-439, 2016.

SOUZA, W. B.; PAULA MELO, L.; LIMA, L. C. S.; SOUZA, D. C.; TEXEIRA, T. T.. Mapeamento e avaliação da potabilidade de água proveniente de fontes alternativas de captação na cidade de Astolfo Dutra. Águas Subterrâneas, v.32, n.3, 2018. DOI: https://doi.org/10.14295/ras.v32i3.29179

A CBPC - Companhia Brasileira de Produção Científica (CNPJ: 11.221.422/0001-03) detém os direitos materiais desta publicação. Os direitos referem-se à publicação do trabalho em qualquer parte do mundo, incluindo os direitos às renovaç̃ões, expansões e disseminações da contribuição, bem como outros direitos subsidiários. Todos os trabalhos publicados eletronicamente poderão posteriormente ser publicados em coletâneas impressas sob coordenação da Sustenere Publishing, da Companhia Brasileira de Produção Científica e seus parceiros autorizados. Os (as) autores (as) preservam os direitos autorais, mas não têm permissão para a publicação da contribuição em outro meio, impresso ou digital, em português ou em tradução. 